\title{
Vacuum Deliveries: A Retrospective Study on Immediate Maternal and Neonatal Outcomes in Western Regional Hospital, Pokhara
}

\section{Deepak Raj Kafle ${ }^{1}$, Prem Raj Pageni ${ }^{1}$}

${ }^{1}$ Department of Obstetrics and Gynecology, Western Regional Hospital, Pokhara Academy of Health Sciences, Pokhara, Nepal

\section{Correspondance:}

Dr. Deepak Raj Kafle, MD

Department of Obstetrics and Gynecology

Western Regional Hospital

Pokhara Academy of Health Sciences

Pokhara, Nepal

Email: drdrkafle215@gmail.com

Article received: Sep 252019

\section{ABSTRACT}

Introduction:The overall rate of operative vaginal delivery is diminishing, but the proportion of operative vaginal deliveries conducted by vacuum is increasing. As forceps assisted delivery requires more skill and has more complications on maternal genital tract, this procedure is being less frequently practiced. By the 1970s, the vacuum extractor virtually replaced forceps for assisted deliveries in most of the countries. Vacuum assisted vaginal delivery reduces maternal as well as neonatal morbidity and mortality in prolonged second stage of labor, non reassuring fetal status and maternal conditions requiring a shortened second stage.

Materials and Methods: This was a record based retrospective study of 217 vacuum assisted vaginal deliveries conducted at Western Regional Hospital, Pokhara for a period of one year. Patient's discharge charts were studied and details of indications for vacuum application, maternal genital tract status, amount of blood loss, postpartum hemorrhage (PPH), birth weight, APGAR score at 1 and 5 minute, Neonatal Intensive Care Unit (NICU) admission and neonatal death (NND) were collected. Descriptive data analysis was done using SPSS program.

Results:Out of the 8778 deliveries conducted during the study period, $217(2.47 \%)$ cases were vacuum assisted vaginal deliveries. No significant adverse obstetrics outcomes were noted. Most frequent indication was fetal distress which accounted for $53.9 \%$. Though $3 \mathrm{rd} / 4$ th degree perineal tears were less, episiotomy rate was higher (69.1\%). Regarding neonatal outcomes, mean APGAR score at 5 minute was $7.42 \pm 1.11 \mathrm{SD}$ and $12.4 \%$ neonates had APGAR score of less than 7 at 5 minute.

Conclusion: When standard criteria for vacuum application are met and standard norms are followed, there is no evidence of adverse obstetrics outcomes in vacuum assisted vaginal delivery. Prompt delivery by a skilled clinician in non reassuring fetal cardiac status reduces neonatal morbidity and mortality.

Keywords: Obstetrics outcomes, Operative vaginal deliveris, Vacuum delivery. 
Original Article

\section{INTRODUCTION}

Operative vaginal delivery refers to a delivery in which the clinician uses forceps or a vacuum device to assist the mother in delivering the fetus to extrauterine life. Globally, about $10-20 \%$ of all deliveries need some form of assistance or intervention at delivery and operative vaginal delivery comprises $6-12 \%$ of these interventions. ${ }^{1}$ Vacuum assisted delivery is a service incorporated into basic and comprehensive emergency obstetrics care program. ${ }^{2}$ Alarming rise in caesarean delivery rate has encouraged many professionals to conduct studies related to operative vaginal delivery. The overall rate of operative vaginal delivery has been diminishing, but the proportion of vacuum deliveries has been increasing. In general, vacuum delivery is safer than forceps for the mother, while forceps are safer than vacuum for the fetus. Vacuum devices areeasier to apply and result in less maternal soft tissue trauma compared to forceps. When used with standard norms, vacuum delivery reduces the maternal as well as neonatal morbidity and mortality.

A maximum of two to three cup detachments, three sets of pulls for the descent phase, three sets of pulls for the outlet extraction phase, and/or a maximum total vacuum application time of 15 to 30 minutes are commonly recommended, with most authors advising lesser time limits. ${ }^{3-5}$ The majority of successful vacuum assisted deliveries are achieved within the parameters described aboveand thus justify their use. A study on 1000 consecutive vacuum assisted deliveries reported $\leq 3$ pop-offs in $99.9 \%$ of cases, use of $\leq 5$ pulls in $98.7 \%$ of casesand duration of cup application $\leq 10$ minutes in $97.4 \%$ of cases. ${ }^{6}$ A cohort study found that $82 \%$ of completed vacuum deliveries occurred with one to three pulls, and that pulling more than three times was associated with neonatal trauma in $45 \%$ of such deliveries. ${ }^{7}$ Hence, it is a wise practice to abandon the procedure if good instrument placement is followed by no progress in descent over three pulls. If descent has occurred and delivery is clearly imminent, then proceeding with instrumental delivery after three pulls may be appropriate and less morbid than a cesarean delivery of a fetus with its head on the perineum.
Medical Journal of Pokhara Academy of Health Sciences Vol. 3 Issue 1 second stage of labor, maternal exhaustion, inadequate maternal expulsive effort, fetal distress and a maternal condition requiring a shortened second stage. ${ }^{8}$ Vacuum devices should not be used to assist delivery prior to 34 weeks of gestation because of the risk of fetal intraventricular hemorrhage. ${ }^{8}$

\section{MATERIALS AND METHODS}

This was a retrospective study conducted at Western Regional Hospital; a tertiary care center located at Pokhara.Delivery records of one year duration from $17^{\text {th }}$ September, 2018 to $16^{\text {th }}$ September, 2019 were reviewed. Patient's discharge charts of vacuum assisted vaginal deliveries (217 cases) were studied and details of indications for vacuum application, maternal genital tract status, amount of blood loss, PPH, birth weight, APGAR score at 1 and 5 minute, need and indication for NICU admission and NND were collected. Data was compiled and analyzed using SPSS program.

\section{RESULTS}

Out of the 8778 deliveries conducted during this study period, $217(2.47 \%)$ cases were vacuum assisted vaginal deliveries.

\section{Figure 1: Age Distribution}

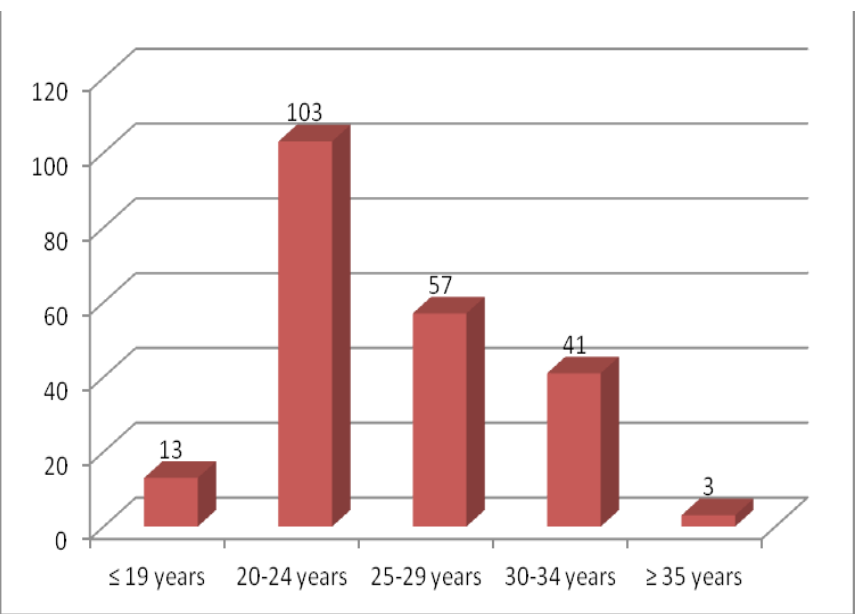

The mean age of women was 25.1 years $\pm 4.37 \mathrm{SD}$. The youngest age was 15 years and the eldest was 35 years. Teenage pregnancy rate was $5.9 \%$ whereas only 3 cases were 35 years. There were $70 \%$ nullipara women. 
Original Article

Figure 2: Gestational age distribution

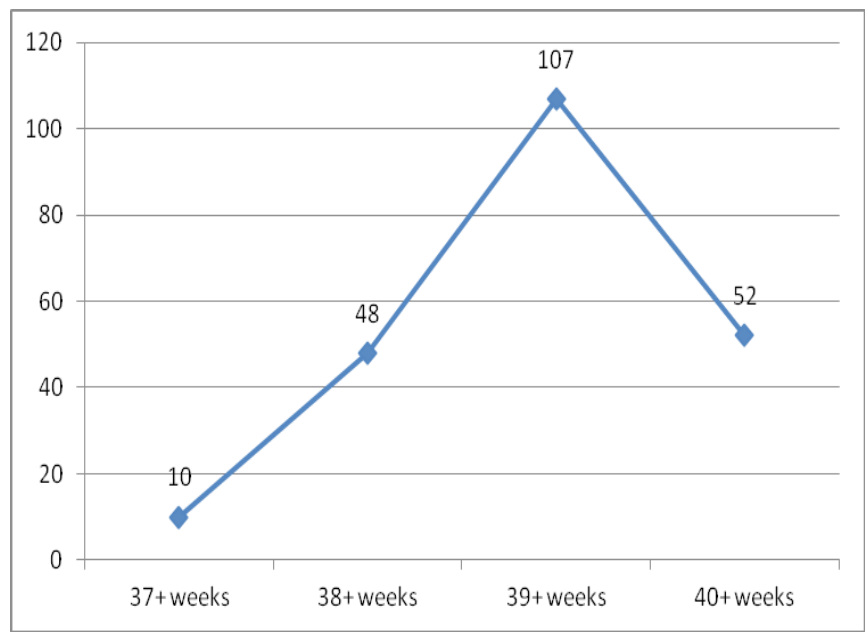

Mean gestational age was 38.98 week $\pm 0.895 \mathrm{SD}$. The percentage of women delivering after 40 week was $24 \%$. Only $4.6 \%$ women delivered at $37+$ week of gestation.

Table 1: Indication for vacuum delivery

\begin{tabular}{|l|c|c|}
\hline \multicolumn{1}{|c|}{ Indication } & Frequency & Percentage \\
\hline $\begin{array}{l}\text { Fetal Distress } \\
\text { (Abnormal fetal heart rate) }\end{array}$ & 11 & $5.1 \%$ \\
\hline $\begin{array}{l}\text { Fetal Distress } \\
\text { (meconium stained liquor) }\end{array}$ & 106 & $48.8 \%$ \\
\hline $\begin{array}{l}\text { Poor maternal } \\
\text { expulsive effort }\end{array}$ & 48 & $22.1 \%$ \\
\hline $\begin{array}{l}\text { Prolonged second } \\
\text { stage of labor }\end{array}$ & 2 & $0.9 \%$ \\
\hline $\begin{array}{l}\text { To cut short } \\
\text { second stage of labor }\end{array}$ & 217 & $100 \%$ \\
\hline Total & $50 \%$ \\
\hline
\end{tabular}

Vacuum was applied in 53.9\% cases for fetal distress. Vacuum delivery was performed in only $0.9 \%$ cases to cut short second stage of labor.

Table 2: Genital tract status

\begin{tabular}{|l|c|c|}
\hline Status of genital tract & Frequency & Percentage \\
\hline Intact perineum & 2 & $0.9 \%$ \\
\hline Planned episiotomy & 150 & $69.1 \%$ \\
\hline $1^{\text {st }}$ degree perineal tear & 19 & $8.8 \%$ \\
\hline $2^{\text {nd }}$ degree perineal tear & 43 & $19.8 \%$ \\
\hline $3^{\text {rd }} / 4^{\text {th }}$ degree perineal tear & 2 & $0.9 \%$ \\
\hline Cervical tear & 1 & $0.5 \%$ \\
\hline Total & 217 & $100 \%$ \\
\hline
\end{tabular}

Vacuum Deliveries: A Retrospective Study. Kafle DR. et. al. There was more practice of planned episiotomy $(69.1 \%)$ and theincidence of $3^{\text {rd }} / 4^{\text {th }}$ degree perineal injury was only $0.9 \%$.

\section{Postpartum Hemorrhage}

The mean estimated blood loss was $140.6 \mathrm{ml} \pm 139.1$ SD. The largest amount of blood loss was $1200 \mathrm{ml}$. There were $2.8 \%$ women who experienced PPH (blood loss $\geq 500 \mathrm{ml}$ ). The percentage of women requiring blood transfusion was $1.3 \%$.

\section{Figure 3: Weight distribution of babies}

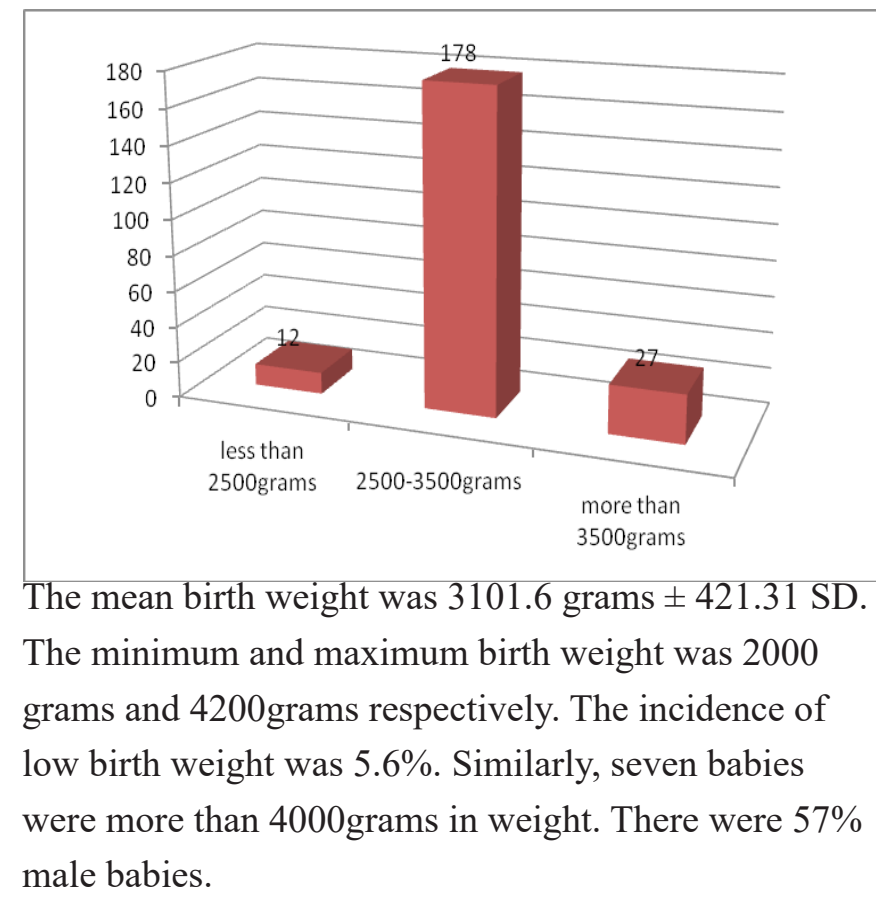

Table 3: APGAR Score $<7$ at 1 minute and $<7$ at 5 minutes

\begin{tabular}{|l|c|c|}
\hline APGAR Score & Frequency & Percentage \\
\hline $\begin{array}{l}\text { Less than } 7 \\
\text { at } 1 \text { minute }\end{array}$ & 139 & $64 \%$ \\
\hline $\begin{array}{l}\text { Less than } 7 \\
\text { at } 5 \text { minutes }\end{array}$ & 27 & $12.4 \%$ \\
\hline
\end{tabular}

The mean APGAR score at 1 minute was $5.90 \pm 1.23$ SD. The percentage of newborn with APGAR score of less than 7 at 1 minute was $64 \%$. The mean APGAR score at 5 minute was $7.42 \pm 1.11 \mathrm{SD}$ and $12.4 \%$ babies had an APGAR score of $<7$ at 5 minute. Nearly $25 \%$ of babies required NICU admission. Perinatal mortality rate was 9.0 per 1000 total live births. 
Original Article

\section{DISCUSSION:}

The primary aim of the study was to analyze the indications of vacuum assisted vaginal delivery and to estimate both maternal and neonatal morbidities following the procedure.Operative vaginal delivery should be abandoned if it is difficult to apply the instrument, descent does not easily proceed with traction, or the baby has not been delivered within a reasonable time of 15 to 20 minutes. $^{9}$ Experts have recommended abandoning the procedure after three pulls. A cohort study found that 82 percent of completed operative deliveries occurred with one to three pulls, and that pulling more than three times was associated with infant trauma in 45 percent of such deliveries. ${ }^{7}$ If not bound to the norms of the procedure, risk of failure and maternal as well as neonatal complications increases. According to this study, no significant adverse obstetrics outcomes were noted. However, significant findings were increased practices of episiotomy and low mean APGAR score at 1 minute.

The rate of vacuum assisted vaginal delivery, $2.47 \%$ found in our study is comparable to the rate of other developing countries. ${ }^{1,10}$ However, it is much lower than the incidence of the European countries. ${ }^{11}$ Incidence of vacuum delivery observed in this study is lower than that reported by Stern $\mathrm{C}$ et $\mathrm{al}^{12}$ as $4 \%$, Lukasse $\mathrm{M}$ et al ${ }^{13}$ as $4.9 \%$ and Penwell $\mathrm{V}$ et a $\mathrm{l}^{14}$ as $5 \%$. These days, cesarean section rate is in increasing trend and it was $26 \%$ in this study. Though vacuum assisted delivery is listed as a component of BEOC and CEOC program, there is hesitancy in its use. ${ }^{15}$ The justifiable explanations for decreasing trends could be poor mastering of the art and fear of related disastrous complications. Again, new practitioners and residents are reluctant in doing operative vaginal delivery thereby increasing the caesarean delivery rate. Only few cases reach the second stage of labor needing operative vaginal delivery.

In this study, more than $70 \%$ vacuum deliveries were performed in 20-29 years age group. This higher rate may be justified with the fact that majority of the women get married by 30 years in developing countries like Nepal.

The percentage of the cases delivered by vacuum
Medical Journal of Pokhara Academy of Health Sciences Vol. 3 Issue 1 application in this study for fetal distress, poor maternal effort and prolonged second stage of labor were 53.9\%, $22.1 \%$ and $23 \%$ respectively. Only $0.9 \%$ cases required shortening of second stage of labor.

Regarding genital tract injury, no significant adverse outcome was observed in this study. However, a practice of episiotomy was higher with the rate of $69.1 \%$.A cohort study found that mediolateral episiotomy during operative vaginal delivery protects against anal sphincter injury. ${ }^{16}$ The possible explanation for lower rate of $3^{\text {rd }} / 4^{\text {th }}$ degree perineal tears in this study could be the higher rate of episiotomy. Seventy percent women were primipara in this study and there is a tendency to give episiotomy in primipara. Perineal laceration or tear heals well and rapidly than inflicted wound. So trend in reducing a practice of episiotomy is rising. As vacuum cup is smaller than fetal head, episiotomy is not necessary in most of the cases for application. A randomized trial comparing routine versus restrictive episiotomy did not show a difference in outcomes, including anal sphincter tear or Postpartum Hemorrhage. ${ }^{17}$

This study found that $2.8 \%$ women experienced $\mathrm{PPH}$ following vacuum assisted vaginal delivery and $1.3 \%$ required blood transfusion. The incidence of $\mathrm{PPH}$ even in spontaneous vaginal delivery observed by Stern $\mathrm{C}$ et $\mathrm{al}^{12}$ as $3.1 \%$ and Penwell $\mathrm{V}^{14}$ as $17 \%$ is higher than the rate recorded in our current study.

The incidence of serious neonatal complications with vacuum extraction is approximately 5 percent. ${ }^{18}$ There were no significant adverse outcomes in terms of APGAR score at 1 and 5 minuteas an indicator of the immediate neonatal prognosis in this study. The mean APGAR score at 1 minute was $5.90 \pm 1.23 \mathrm{SD}$. The percentage of newborn with APGAR score of less than 7 at 1 minute was $64 \%$. Fetal distress, a major indication for vacuum delivery which counted for nearly 54\% could be the possible contributing factor for this low 1 minute APGAR score. Apgar score at 5 minutes is a better reflection of subsequent neonatal outcome than at 1 minute and most studies have taken this parameter to compare neonatal outcomes. The mean APGAR score at 5 minutes was $7.42 \pm 1.11 \mathrm{SD}$ and $12.4 \%$ babies had APGAR score $<7$ at 5 minute in our study. Nearly $25 \%$ of babies required NICU admission. When compared 


\section{Original Article}

with other studies, this rate of NICU admission is higher. However, this rate is acceptable as there is a policyto observe neonates born by vacuum in NICU. Perinatal mortality rate calculated in this study is 9.0 per 1000 total live births which is comparable to other studies as well.

\section{CONCLUSION:}

When standard criteria for vacuum application are met and standard norms are followed, there is no evidence of adverse obstetrics outcomes in vacuum assisted vaginal delivery. Prompt delivery using vacuum extractor by a skilled clinician in non reassuring fetal cardiac status reduces neonatal morbidity and mortality.

\section{REFERENCES}

1. Onoh RC, Ezeonu PO, Chijioke O, Onoh TP, Saidu AK, Ezeonu CT. Disappearing art of forceps delivery and the trend of instrumental vaginal deliveries at Abakaliki, Nijeria. Afr J Med Health Sci. 2014; 13: 99-104.

2. WHO, UNICEF. Guidelines for monitoring the availability and use of obstetric services. New york: WHO, UNICEF, 1917.

3. Miksovsky P, Watson WJ. Obstetric vacuum extraction: state of the art in the new millennium. ObstetGynecolSurv 2001; 56:736.

4. Vacca A. Vacuum-assisted delivery: an analysis of traction force and maternal and neonatal outcomes. Aust N Z J ObstetGynaecol 2006; $46: 124$.

5. Johanson RB, Rice C, Doyle M, et al. A randomised prospective study comparing the new vacuum extractor policy with forceps delivery. Br J ObstetGynaecol 1993; 100:524.

6. Baskett TF, Fanning CA, Young DC. A prospective observational study of 1000 vacuum assisted deliveries with the OmniCup device. J ObstetGynaecol Can 2008; 30:573.

7. Murphy DJ, Liebling RE, Patel R, et al. Cohort study of operative delivery in the second stage of labour and standard of obstetric care. BJOG 2003; 110:610.
Vacuum Deliveries: A Retrospective Study. Kafle DR. et. al.

8. American College of Obstetricians and Gynecologists. Operative vaginal delivery. ACOG Practice Bulletin number 17, American College of Obstetricians and Gynecologists, Washington, DC 2000.

9. Edozien LC. Towards safe practice in instrumental vaginal delivery. Best Pract Res ClinObstetGynaecol 2007; 21:639.

10. Kadas AS, Alliyu LD, Hauwa MA. Instrumental delivery in Bauchi, Northest Nigeria; J west Afr college surg. 2011: 1(4): $18-27$

11. Noton F. International difference in the use of obstetric interventions. JAMA. 1990; 263 (24): 3286-91.

12. Stern C, Permezel M, Petterson C, Lawson J, Eggers T, Kloss M. The Royal Women's Hospital Family Birth Centre: the first 10 years reviewed. Aust N Z J ObstetGynaecol. 1992; 32(4): 291-6.

13. Lukasse M, Qian P, Aamodt G. A midwife-led birthing unit. Tidsskr Nor Laegeforen. 2006; 126(2): 170-2.

14. Penwell V. Mercy in action. Philippine birth center statistics. Midwifery Today Int Midwife. 2004; 70: 56-57.

15. Lamichhane B, Singh A. Changing trends of instrumental deliveries at Patan Hospital. NJOG. 2015; 20 (2): 33-5.

16. de Leeuw JW, de Wit C, Kuijken JP, Bruinse HW. Mediolateral episiotomy reduces the risk for anal sphincter injury during operative vaginal delivery. BJOG 2008; 115:104.

17. Murphy DJ, Macleod M, Bahl R, et al. A randomised controlled trial of routine versus restrictive use of episiotomy at operative vaginal delivery: a multicentre pilot study. BJOG 2008; 115:1695.

18. Robertson PA, Laros RK Jr, Zhao RL. Neonatal and maternal outcome in low-pelvic and midpelvic operative deliveries. Am J ObstetGynecol 1990; 162:1436. 